\title{
Aguaruna speculative clause: Evidentiality meets focus
}

\author{
Benjamin Rozonoyer*
}

\begin{abstract}
The speculative clause in Aguaruna presents us with two distinctive and interacting semantic phenomena - evidentiality and focus - both of which have been objects of recent interest cross-linguistically. Following the alternative semantics theory of focus developed by Rooth (1992), I analyze Aguaruna's alternating speculative focus enclitics, and incorporate the evidentiality-focus complex into a compositional semantics for Aguaruna. By formally modeling the interplay of evidentiality and focus, this analysis hopes to glean a more precise understanding of each phenomenon individually, and to contribute to a more complete typology of both.
\end{abstract}

Keywords. Aguaruna; Chicham; evidentiality; focus; alternative semantics

1. Introduction. This paper analyzes the interaction of focus with the speculative evidential modality in Aguaruna, an indigenous language of northern Peru belonging to the Chicham family. ${ }^{1}$ Among the indicative clauses in Aguaruna, the speculative clause exhibits a clean and compact paradigm of focus marking. According to Overall (2018), the focus enclitic in the speculative clause (one of a handful of enclitics in Aguaruna that contribute a focusing effect to their host) "has the least semantic content, and appears to have the sole function of marking the focus of speculative modality".

This paper is structured as follows. In $\S 2$ I present a basic characterization of Aguaruna and of the speculative clause with its internal distribution of focus particles; in $\S 3$ I argue for the value of the speculative operator independently of focus interaction; in $\S 4$ I present the alternative semantics theory of focus interpretation developed by Rooth (1992) and apply this intuitive framework to Aguaruna's speculative focus in $\S 5$. In $\S 6$ I conjecture about some basic diagnostics to categorize the meaning of the speculative clause for the purpose of integrating its unique focus paradigm into the typology of evidential systems.

2. Aguaruna and the speculative clause. Aguaruna is a nominative-accusative SOV language with a synthetic, agglutinative morphology that is entirely suffixing. The speculative clause, among the 13 overall clause types in Aguaruna, is one of 4 types of indicative clauses - declarative, counter-expectation, narrative and speculative - each conveying the epistemic distinction their name suggests. This categorization conforms to the requirements for clausehood discussed in Sadock \& Zwicky (1985) in that it is uniquely marked, and can not co-occur with markers designated for any other independent clause type.

Not surprisingly, the verb is the primary bearer of epistemic markers. A number of verbal suffix positions serve to host valency, TAM, negation and subject/object agreement morphol-

\footnotetext{
*I am indebted to Sophia Malamud for guiding and supporting me in this research. I would also like to extend my gratitude to Simon Overall, whose grammar of Aguaruna made this work possible. Author: Benjamin Rozonoyer, Brandeis University (brozonoyer@brandeis.edu)

${ }^{1}$ All data about Aguaruna comes from Overall's grammar, whose glossed examples follow the Leipzig conventions. Other glosses found in his examples are: DS=different subject, IFUT=immediate future, RECPST=recent past, SPEC=speculative; ':' separates semantically identifiable morphemes in a portmanteau, ' + ' separates phonologically identifiable forms that cannot be segmented. Additionally, I use $F_{\text {SPEC }}$ as opposed to SPEC to denote focus marking within the speculative clause.
} 
ogy on finite verbs; the last position houses markers for mood. Table 1 below illustrates the morphology of the finite verb in Aguaruna.

\begin{tabular}{cccccccc}
\hline & A & B & C & D & E & F & G \\
ROOT & VALENCY & OBJECT & ASPECT & NEGATION & TENSE & SUBJECT & MOOD \\
\hline
\end{tabular}

Table 1. A (simplified) scheme of Aguaruna finite verbal morphology (Overall 2018:15) Within such finite verbs (i.e. verbs necessarily inflected for tense and mood/modality, unlike those in subordinate clauses which are not inflected for mood), the different paradigms for mood "[cover] traditional speech acts as well as epistemic and attitudinal distinctions". Verbal slot $G$ generally serves to host modality marking (except in the narrative modality, which is conveyed by the grammaticalized independent post-verbal morpheme tuwahami்). We can see the declarative suffix $-i$ appear in slot $G$ on the predicate of the following declarative clause in (1), fused with the 3rd person subject agreement marker:

(1) íkamỹã̃̃ãã kuchín isak $\tilde{\dot{i}}$

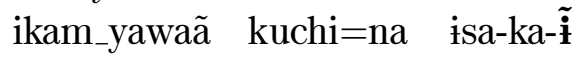

jaguar pig=ACC bite-PFV-3+DECL

'the jaguar has devoured the pig'

(Overall 2018:333)

The speculative clause is invariably marked with the verbal suffix -tai in slot G of the main verb to convey speculative epistemic modality. As seen in (2) below, -tai may serve as the only marker of the speculative mood in a finite clause:

\section{(2) wainkámatai \\ waina-ka-ma-tai \\ see-PFV-RECPST:3-SPEC \\ 's/he probably saw'}

(Overall 2018:379)

Given the absence of an equivalent English construction, the speculative modality is translated periphrastically, using modal verbs such as might or adverbs indicating speculation, as in (2). Overall (2018) describes the speculative mood as "an epistemic marker that expresses the speaker's lowered degree of commitment to the truth of the proposition expressed in the marked clause".

The speculative clause commonly features the focus enclitic $=t s u$ that focuses speculation on a specific constituent:

(3) numinás tsupíktaytai

numi=na=tsu tsupi-ka-ta-ha-tai

tree $=$ ACC $=\mathbf{F}_{\text {SPEC }}$ cut-PFV-IFUT-1SG-SPEC

'perhaps it's wood that I'll cut'

(Overall 2018:378)

$=t s u$ in (3) attaches to the direct object, and focuses tree [wood] as the object of speculation, rather than the entire prejacent proposition I will cut wood. This effect is conveyed in English by the clefted translation. The enclitic =tsu may attach to NPs, as in (3), or to entire subordinate clauses as in (4) (but never to main verbs): 
(4) kantáshhãi bitík asámtãis tíu áinatai

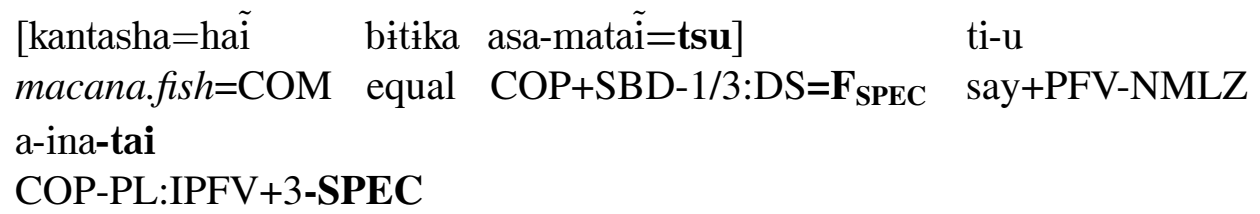

'they say that [because] (probably) it's the same as a macana fish' (Overall 2018:378)

In (4) $=t s u$ accompanies the embedded clause, focusing the speculation on the embedded clause it's the same as a macana fish, rather than on they say, which is epistemically unmarked. ${ }^{2}$

The enclitic $=t s u$ alternates with a verbal suffix - $t s a$, which is "presumably cognate", and forms a complex suffix together with -tai on the main verb when the entire proposition undergoes speculation. A comparison between (3) and (5) demonstrates the effect of this alternation:

\section{(5) numín tsupíktantsatai \\ numi=na tsupi-ka-ta-ha-tsa-tai \\ tree=ACC cut-PFV-IFUT-1SG-F SPEC $_{-}$-SPEC \\ 'I might cut wood'}

(Overall 2018:378)

For lack of data, there are two potential interpretations of the scoping of speculation in (5). In the first interpretation, parallel with (2), doubt is cast by the speaker on the entire prejacent proposition I will cut wood. In the other reading, the speculative operator takes scope over the VP, leaving the first-person subject as the restrictor of the quantification. ${ }^{3}$ These respective interpretations of (5) can serve as answers to different underlying questions under discussion (QUD) (Roberts 2012). If we take the entire prejacent proposition, including its subject, to be the nuclear scope of the speculative operator, we may easily envision it as a response to a QUD such as What next?, to which a proposition with any subject (e.g. $\checkmark$ I might take a nap or $\checkmark$ she might fly to Vancouver) would be a semantically acceptable answer. On the other hand, treating the first-person subject as a fixed restrictor and interpreting speculation over the matrix VP alone would restrict the possible QUD's to a set of the form What will happen to you next?, to which the addressee could felicitously respond with a proposition of the form $\checkmark$ I might take a nap, but not \# she might fly to Vancouver.

We will weigh the evidence for these approaches in $\S 5$, and temporarily represent this effect (whether at-issue or not) as simply Speculate Sp $_{s p}(p)$, where $p=I$ will cut wood and the subscript (which we will omit in practice for cleanliness) points to the speaker who is doing the speculation.

Scoping interpretations aside, we note that the alternating enclitics alone contribute to the difference in meaning between (3) and (5), which are otherwise identical and identically marked for speculative epistemic modality. Table 2 below summarizes the distribution of these particles, as evidenced from representative examples (3), (4) and (5).

Can a single semantic mechanism for $=t s u$ and $-t s a$ account for their effect on meaning? Their phonetic correspondence and complementary distribution suggests allomorphy, which

\footnotetext{
${ }^{2}$ To more accurately reflect the scoping of speculation in (4), I slightly adapted Overall's original translation they probably say that because (they think) it's the same as a macana fish.

${ }^{3}$ See Partee 1991 for the tripartite structure of quantification in terms of operator, restrictor and nuclear scope.
} 


\begin{tabular}{|c|l|}
\hline$=t s \boldsymbol{u}$ & $\begin{array}{l}\text { Attaches to an NP or subordinate clause within the speculative-marked proposition, } \\
\text { focusing the host constituent as the object of speculation. }\end{array}$ \\
\hline $\boldsymbol{- t s \boldsymbol { a }}$ & Attaches to the main verb when the entire proposition is the object of speculation \\
\hline
\end{tabular}

Table 2. Distribution of $=t s u$ and $-t s a$

would implicate a single semantic value. ${ }^{4}$ And the exclusively focusing function of $=t s u$ demarcates that we should model both these particles in the framework of focus interpretation. But before we can model the role of these optional enclitics, we have to determine the value of the speculative marker -tai which invariably appears in every grammatical speculation of Aguaruna.

3. Modeling the speculative operator. We begin, as Rooth (1992), with a basic assumption of a compositional semantics for the interpretation of Aguaruna, in which the syntactic structure of a sentence governs the composition of its constituent phrases into a proposition with a boolean truth value. Hence, taking $E$ to be the domain of entities and $T$ to be the set of truth values, we can view the transitive predicate bite in sentence (1) as a two-place function of type $E \rightarrow(E \rightarrow T)$, which composes sequentially with its arguments pig and jaguar to yield the proposition corresponding to (1) the jaguar has devoured the pig. ${ }^{5}$ Note that the composition will respect the SOV ordering in an Aguaruna sentence:

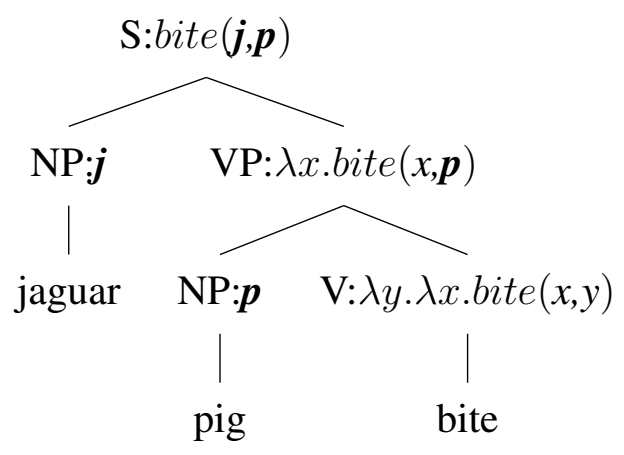

How do we incorporate the evidential operator -tai, which appears in any and every speculative clause, into the semantic interpretation? Inspiration can be drawn from (2) (repeated here as (7)), which is as basic as the speculative clause goes, and is unmarked for focus:

(7) wainkámatai

waina-ka-ma-tai

see-PFV-RECPST:3-SPEC

's/he probably saw'

The unfocused speculation in this example takes scope over the prejacent proposition $p=s / h e$ saw, and (as noted in §2) may plausibly be viewed as a sentence-level modifier that we can

\footnotetext{
${ }^{4}$ I use the term 'allomorphy' with caution since the conditioning seems to be purely syntactical, as opposed to phonological or morpholexical (cf. Spencer 1991). Perhaps a historical explanation can do the alternation more justice.

${ }^{5}$ For simplicity I leave tense and aspect out of the interpretation tree.
} 
represent as Speculate $(p)$. This consideration leads us to treat epistemic modality as the outermost function in the semantic interpretation of an Aguaruna indicative clause, and consequently as the outermost layer of the interpretation tree (this seems to be supported by the position of -tai in the outermost verb slot G). The logical syntactic tree for (7) would therefore be used by the semantics to obtain a speculative proposition (first combining saw with the 3rd person subject marker, and then applying -tai to the output). A preliminary semantic value for the speculative mood marker -tai can look like:

$$
\llbracket \text {-tai } \rrbracket=\lambda p . S p e c u l a t e(p), \quad p \in T \quad \text { (preliminary) }
$$

On this basis, the interpretation of (7) is straightforward (given that Aguaruna is a null-subject language, we assume the presence of a phonetically null 3rd person subject $s$ in the syntactic tree):

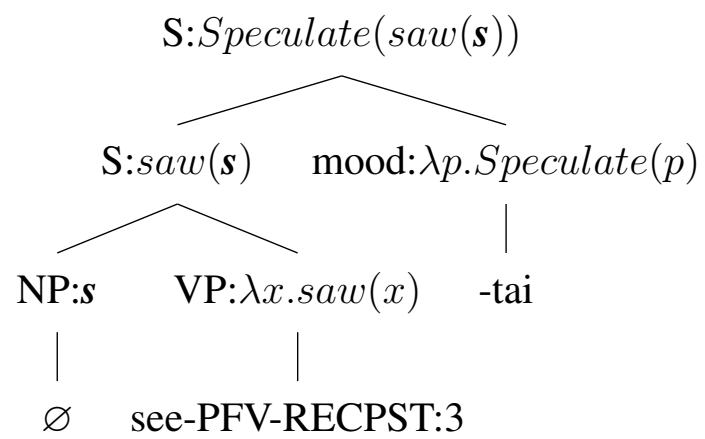

Although adequate for (9), the preliminary definition of -tai does not take into account the necessity of epistemic alternatives in order for speculation to be felicitous. In other words, to sincerely speculate about $p$, where $p=$ she saw, the speaker must have a set (call it $C$ ) of alternative speculations in his information state that includes $p$ but also contains at least one proposition other than $p$, e.g. $C=\{$ she saw, she heard, she didn't see, ... $\}$. Currently, we cannot say anything more specific about what alternative propositions go into $C$. Only in the presence of focus, as we shall see very shortly in $\S 4$, will the structure of such alternative propositions be in part constrained by the location of the focus feature within the sentence. ${ }^{6}$

Treating Speculate as an atomic function over $p$ and $C$ that imposes no requirements on $C$ except that it contain the uttered proposition $p$ and at least one alternative to it, we augment (8) by incorporating $C$ as an additional parameter of -tai:

$$
\llbracket \text {-tai } \rrbracket=\lambda p . \lambda C . \text { Speculate }(p, C), \quad p \in T, C \text { is the speculator's set of alternatives for } p
$$

This updated formula does not complicate the interpretation of (9), except that the parameter $C$ must now be filled at the root node by an extra-linguistically determined set of alternatives to the prejacent proposition.

\footnotetext{
${ }^{6} \mathrm{At}$ this point we may ask about the inner-workings of this set $C$ of alternative propositions required for speculation. What does it mean, in terms of $C$, to speculate that a certain proposition is true? Does the fact that the speculated proposition $p$, rather than some other proposition in $C$, surfaces in the utterance presuppose a likelihood-based ordering on the elements of $C$ that ranks $p$ above the other propositions? Such questions pertaining to the nature of speculation are outside the scope of this paper.
} 
Placing focus on some constituent within $p$ clearly provides more specific information about the alternatives to $p$ that we have in mind. In the words of Rooth (1992), we may "use the focus semantic value to constrain $C$, leaving room for a pragmatic process of constructing a domain of quantification to add further information [about the alternatives]". The variable $C$ supplied by the speculative operator will simultaneously be constrained by, and indispensable to, successful focus interpretation, a theory of which I now proceed to describe. ${ }^{7}$

4. Rooth's alternative semantics interpretation of focus. Rooth (1992) incorporates focus into the compositional framework for English as "an additional semantic value". Following Rooth's notation, $\llbracket \cdot \rrbracket^{\circ}$ is taken to mean the default unfocused semantic interpretation of phonetic material (e.g. $\llbracket$ jaguar $\rrbracket^{\circ}=\boldsymbol{j}$ ), as opposed to its focused interpretation $\llbracket \cdot \rrbracket^{f}$, which we define promptly. Focus interpretation is applicable only to material that is phonetically marked for focus - and we will denote focus marking with the feature subscript $[\cdot]_{F}$. Note that in English, $F$ consists solely of intonation, and has no other phonetic value.

Intuitively, a focused constituent emphasizes the existence of alternatives for it, while simultaneously contributing its unfocused semantic value to the compositional meaning of the larger constituent. Consider Rooth's scenario of a party at which Mary introduces a male to a female. The twofold role of focus can be seen in the contrasting accounts below, which differ only in the location of focus intonation:

\section{(11) a. Mary only introduced $[\text { Bill }]_{F}$ to Sue.}

b. Mary only introduced Bill to $[\mathrm{Sue}]_{F}$.

(11a) connotes the existence of alternatives to Bill $\left(\llbracket\right.$ Bill $\left.\rrbracket^{\circ}=\boldsymbol{b}\right)$ whom Mary might introduce to Sue (perhaps Charlie and Doug), whereas (11b) suggests the existence of candidates other than Sue to whom Mary might introduce Bill (e.g. Alice and Emma). This explains the infelicity of saying (11a) when the only male at the party is Bill, or (11b) when the only female at the party besides Mary is Sue.

This intuition can be formalized by defining the focus value of some phrase $\alpha$ as the set obtained by pointwise substitution of the focused constituent with every possible alternative for it (this set will include both $\alpha$ 's ordinary semantic value $\llbracket \alpha \rrbracket^{\circ}$, and at least one contrasting value). Given our hypothetical party scenario, the focus values for the atomic nouns Bill and Sue are $\llbracket[\text { Bill }]_{F} \rrbracket^{f}=\{\boldsymbol{b}, \boldsymbol{c}, \boldsymbol{d}\}$ and $\llbracket[\mathrm{Sue}]_{F} \rrbracket^{f}=\{\boldsymbol{s}, \boldsymbol{a}, \boldsymbol{e}\}$. The alternatives in the focus interpretation of both Bill and Sue may theoretically be the entire set of entities $\{\boldsymbol{a}, \boldsymbol{b}, \boldsymbol{c}, \boldsymbol{d}, \boldsymbol{e}, \boldsymbol{s}$, $\ldots\}$, although extra-linguistic knowledge (here, the fact that only people can be objects of introduction at parties, plus the gender divide) will likely constrain the domain of quantification. The focus semantic value (alternative set) $\llbracket \alpha \rrbracket^{f}$ for some non-atomic phrase $\alpha$ that contains a focused constituent (e.g. the VP introduced [Bill] $]_{F}$ to Sue) is obtained recursively via a pointwise composition of all the alternatives present in $\alpha$ 's focused constituents (cf. Rooth 2016). ${ }^{8}$ Hence, the resulting alternatives for the VPs in (11a) and (11b) are, respectively:

\footnotetext{
${ }^{7}$ The acquainted reader can skip directly to $\S 5$.

${ }^{8}$ I illustrate this process for an Aguaruna sentence in $\S 5,(20)$
} 


$$
\begin{aligned}
& \text { a. } \llbracket \text { introduced }[\text { Bill }]_{F} \text { to Sue } \rrbracket^{f}=\{\lambda x \text {.introduce }(x, y, s) \mid y \in E\} \\
& =\{\lambda x . i n t r o d u c e(x, \boldsymbol{b}, \boldsymbol{s}), \lambda x . i n t r o d u c e(x, \boldsymbol{c}, \boldsymbol{s}), \lambda x . i n t r o d u c e(x, \boldsymbol{d}, \boldsymbol{s}), \ldots\} \\
& \text { b. } \llbracket \text { introduced Bill to }[\text { Sue }]_{F} \rrbracket^{f}=\{\lambda x \text {.introduce }(x, \boldsymbol{b}, z) \mid z \in E\} \\
& =\{\lambda x . \operatorname{introduce}(x, \boldsymbol{b}, \boldsymbol{s}), \lambda x . i n t r o d u c e(x, \boldsymbol{b}, \boldsymbol{a}), \lambda x . i n t r o d u c e(x, \boldsymbol{b}, \boldsymbol{e}), \ldots\}
\end{aligned}
$$

Rooth (1992) proposes a generalized interpretation of focus on the basis of these definitions. Interpretation takes place at the level of the appropriate syntactic constituent before ordinary semantic composition applies. The requirement for alternatives to exist in order for focus interpretation to be valid is formalized by introducing a free variable during focus interpretation, and necessitating this variable to be filled by a linguistically or extra-linguistically determined antecedent of corresponding type. We cite the Focus Interpretation Principle (FIP) (Rooth 1992:86), arrived at after an examination of focus effects in English with the adverb only, contrasting phrases, scalar implicature and question-answer pairs:

(13) (FIP) In interpreting focus at the level of a phrase $\alpha$, add a constraint that:

(contrasting set) $\quad \Gamma \subseteq \llbracket \alpha \rrbracket^{f}$, or (contrasting individual) $)^{9} \quad \gamma \in \llbracket \alpha \rrbracket^{f}$

$\Gamma$ is a variable (introduced by the focus operator $\sim$ on the level at which focus is interpreted) with the type of a set of objects matching $\alpha$ in type, and $\gamma$ is a variable matching $\alpha$ in type.

We observe the FIP at work in the English question-answer instance:

Q: Who cut Bill down to size?

A: $[\text { Mary }]_{F}$ cut Bill down to size.

The focus on Mary is interpreted at the level of the entire answer proposition ( $\alpha=[\text { Mary }]_{F}$ cut Bill down to size), implicating a set of alternative propositions indicated in the discourse tree (15) below (Rooth 1992:88) by the free variable $B_{7}$, which plays the role of $\Gamma$ in the FIP and is introduced by the $\sim$ operator on the level of focus interpretation:

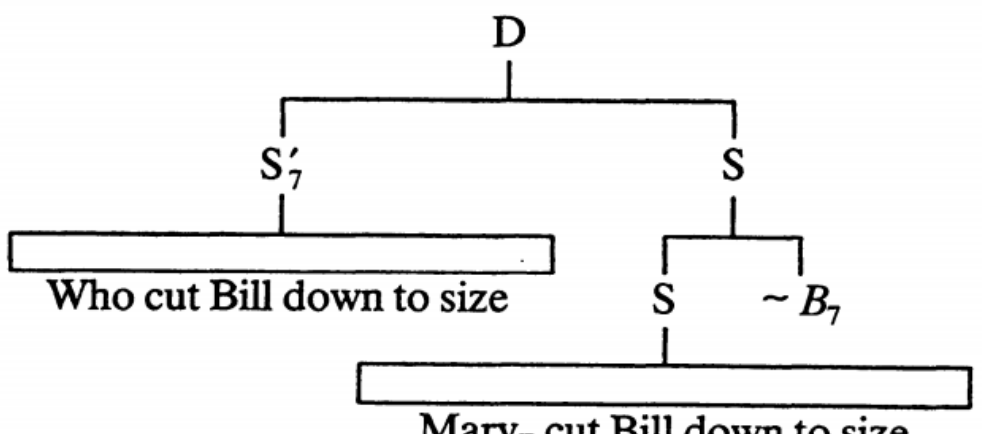

Mary $_{F}$ cut Bill down to size

\footnotetext{
${ }^{9}$ The contrasting individual disjunction of the FIP covers the focus phenomenon of contrasting phrases within the same sentence, e.g. "an American farmer was talking to a Canadian farmer" (see Rooth 1992:79-82). My analysis of Aguaruna focus particles will only reference the contrasting set constraint.
} 
Thus,

$$
\llbracket \alpha \rrbracket^{f}=\{\text { cut_down_to_size }(x, \boldsymbol{b}) \mid x \in E\}
$$

i.e. the focus value of $\alpha$ is the set of propositions whose predicate is restricted to the VP cut Bill down to size, and we must look for an antecedent to $B_{7}$ that is a subset of this focus value. This antecedent comes from the original question Who cut Bill down to size? whose ordinary semantic value can be interpreted (given the personal interrogative pronoun who) as the set of people who cut Bill down to size:

$$
\llbracket \mathrm{S}_{7}^{\prime} \rrbracket^{\circ}=\{\operatorname{person}(x) \wedge \text { cut_down_to_size }(x, \boldsymbol{b}) \mid x \in E\}
$$

Since the question $\llbracket S^{\prime}{ }_{7} \rrbracket^{\circ}$ is, by virtue of set intersection, a proper subset of $\llbracket \alpha \rrbracket^{f}$ (and contains as an element the unfocused value $\llbracket \alpha \rrbracket^{\circ}$ of the answer) it may validly serve as the antecedent for $B_{7}$, so our interpretation of focus succeeds (as $\mathrm{S}$ does, in fact, provide a valid answer to $\llbracket S^{\prime}{ }_{7} \rrbracket^{\circ}$ in the discourse structure D). The remaining semantic interpretation proceeds in the standard way, using $\boldsymbol{m}$ as the unfocused value of Mary to derive the truth-conditions for S.

This alternative semantics for the interpretation of focus provides a framework in which we can model the focused examples of the Aguaruna speculative clause.

5. Aguaruna speculative clause: an alternative semantics analysis. Recall the sole focusmarking role of the alternating enclitic/suffix $=t s u /$-ts $a$ in the speculative modality, with no other independent semantic content. It is therefore analogous to the intonation feature of English focus. Let us set the focus feature $F$ in Aguaruna to $/=t s u /$, or whatever is underlying, assuming that both particles derive from the same form. Returning to (3) (cited again as (18)), we replace $=t s u$ with the speculative focus feature $F_{\text {SPEC }}$ (the subscript is there only to remind the reader of the limited distribution of this feature) on its NP host:

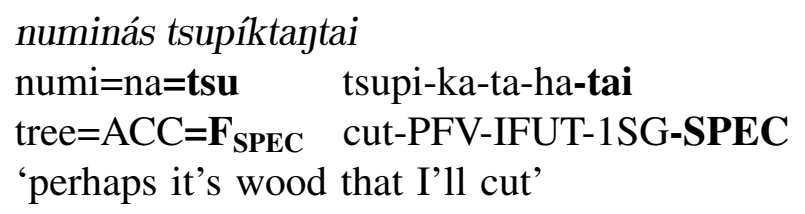

In drawing the rough tree for this focused speculative clause, we will (similarly to (15)) interpret the focused NP (denoted by subscript $F$ in the tree) at the sentential level by introducing the free variable $\Gamma$ with the focus operator $\sim$ at the level of the lowest $S$ node: 


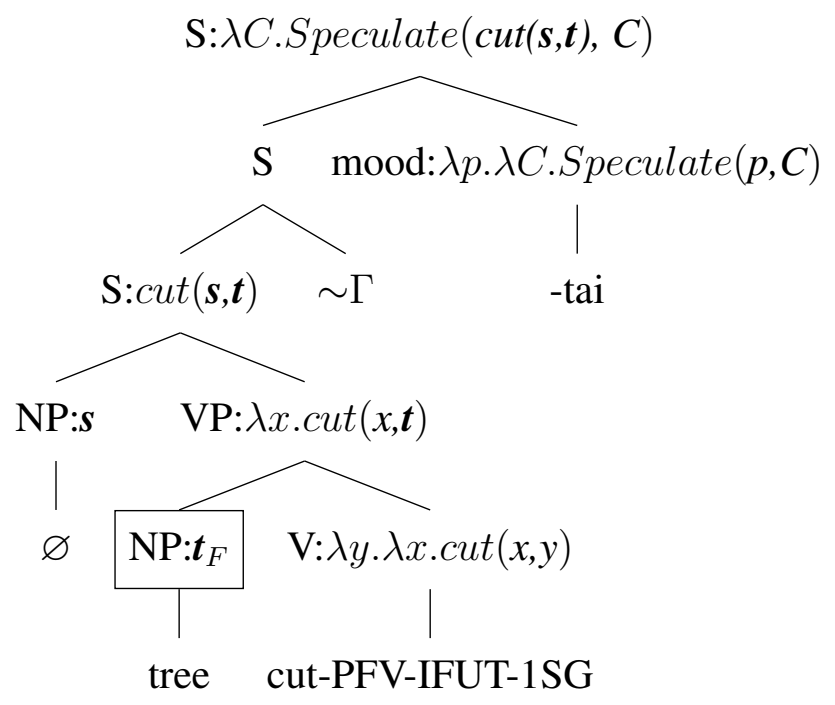

The focus interpretation of the lowermost $\mathrm{S}$, as noted before, takes place in parallel with ordinary semantic interpretation. The interpreted focus semantic value of the lowermost $\mathrm{S}$ in the tree is $\llbracket \mathbf{S} \rrbracket^{f}=\{$ will_cut $(\boldsymbol{s}, x) \mid x \in E\}$, obtained compositionally as in (20) (by $\boldsymbol{s}$ we denote the speaker, and for the domain of entities we let $E=\{\boldsymbol{s}, \boldsymbol{w}, \boldsymbol{u}, \boldsymbol{v}\})$ :

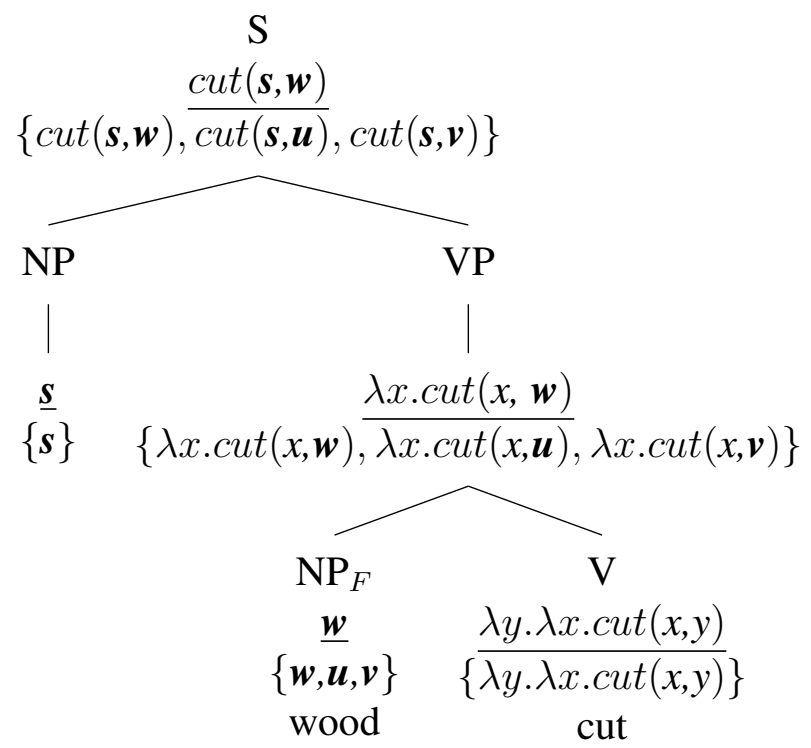

We will omit the bulky pointwise derivation of the focus-interpreted constituent in the future sentences (cf. Rooth 2016). In (19), $\Gamma$ must be bound to an antecedent that is a subset of the focus value of the sentence, $\llbracket \mathrm{S} \rrbracket^{f}$, as stipulated by the FIP in (13). What semantic object in (19) is a subset of $\llbracket S \rrbracket^{f}$, and also contains the ordinary semantic value of the sentence, $\llbracket S \rrbracket^{\circ}$ ? As discussed toward the end of $\S 3, C$ is such a set of epistemic alternatives to $\llbracket \mathrm{S} \rrbracket^{\circ}$. Furthermore, the focus feature on the direct object NP wood within the prejacent proposition indicates that it is also the nuclear scope of the speculation - hence the speaker's set of epistemic alternatives to the prejacent proposition must have the form $\{$ will_cut $(\boldsymbol{s}, x) \mid x \in E\}$ (e.g. $C=\{I$ 
will cut wood, I will cut reeds, I will cut wages\}). Such a $C$, provided to the semantics as the speaker's extra-linguistic speculative set of alternatives at the upper $\mathrm{S}$ node of the interpretation, would be a valid antecedent for $\Gamma$ that allows focus interpretation to be successful.

Let us apply this mechanism to the focus interpretation of sentence (5) (presented here as (21)) with -tsa. Again, we take -tsa to simply mark focus on the main verb:

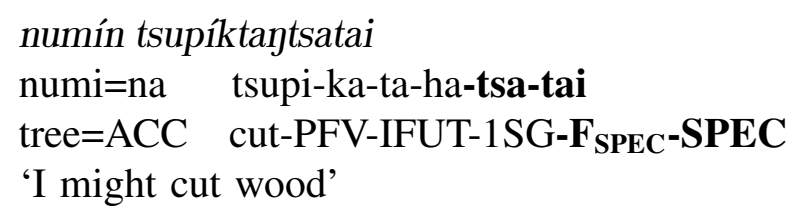

The question now is whether -tsa takes the same broad scope as -tai over the entire proposition, or narrow scope over the verb cut. The English translation of (21) seems to focus speculation on the entire proposition by means of modal might, which favors the broad scoping approach (Von Fintel \& Gillies 2007). The fact that -tsa focuses the predicate of the clause also permits this reading. In the first and second recent past forms of the verb, however, -tsa-tai is broken up by the person marker in the subject agreement slot F (cf. Table 1), so the ending in (21) for recent past would be -tsa-ha[1SG]-ta (Overall 2018:380). If this minor ordering difference is a factor in determining scope, this observation would favor the narrow interpretation of -tsa which leaves the subject outside of the quantification. Overall characterizes -tsa-tai as a "complex suffix" that goes in verbal slot G, but leaves the question of scoping unanswered. I illustrate the conservative interpretation in (22) below by scoping the focus over the VP, but not the subject of a finite clause (hence the focus on the VP node rather than S):

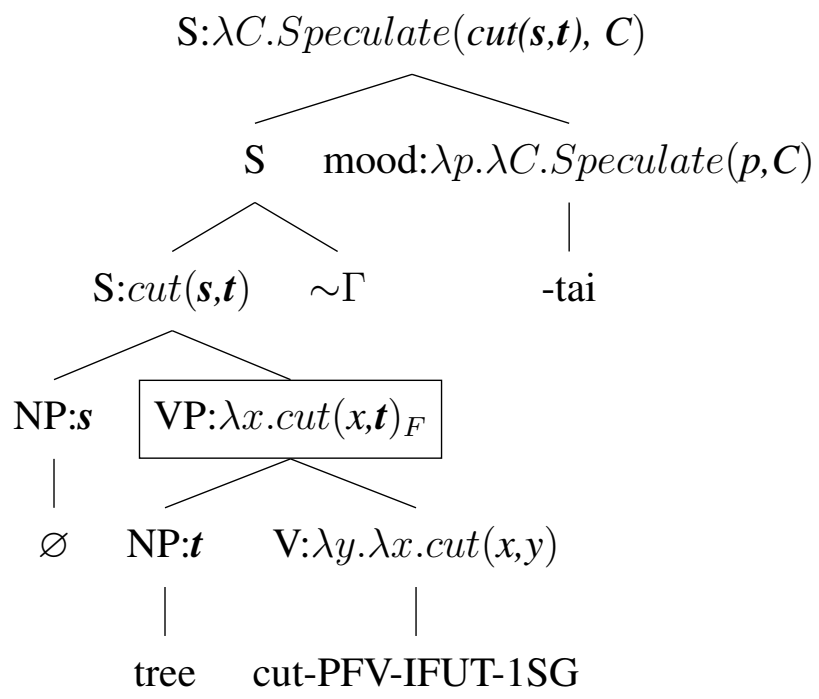

In contrast to (18), the focus value of the unmodalized sentence (21) is the set of sentences whose subject (restrictor) is fixed to the speaker, and whose predicate is recursively obtained from the set of alternatives $\llbracket \mathrm{VP} \rrbracket^{f}$ and their propagation up the tree, in the same manner as in (20) above. In set-theoretic notation, $\llbracket \mathbf{S} \rrbracket^{f}=\{R(\boldsymbol{s}) \mid R: E \rightarrow T\}$, where $R$ is the set of oneargument predicates whose composition with a subject in the domain of entities $E$ results in a boolean proposition. In other words, $\llbracket S \rrbracket^{f}$ is the set of properties that apply to the speaker 
$\boldsymbol{s}$, such as $\boldsymbol{s}$ cuts reeds, $\boldsymbol{s}$ sleeps, or $\boldsymbol{s}$ is baking her aunt a cupcake. The antecedent to $\Gamma$ must consequently be a set of propositions whose subject is set to the speaker, and that includes the pronounced proposition I will cut wood along with at least one alternative. Speculative operator -tai supplies such an antecedent by requiring the set of alternatives $C$, which, given the nature of the speculation, comes in the pragmatically-determined form $\{R(\boldsymbol{s}) \mid R(\boldsymbol{s}) \in E p i(\boldsymbol{s})\}$, where $E p i(s)$ stands for the set of the speaker's epistemic alternatives to her own speculated course of action (i.e. propositions in which she is the subject, equivalently the set of properties that applies to her).

It is not difficult to extend this analysis to a focused subordinate clause, as appeared in example (4) (cited here again as (23)):

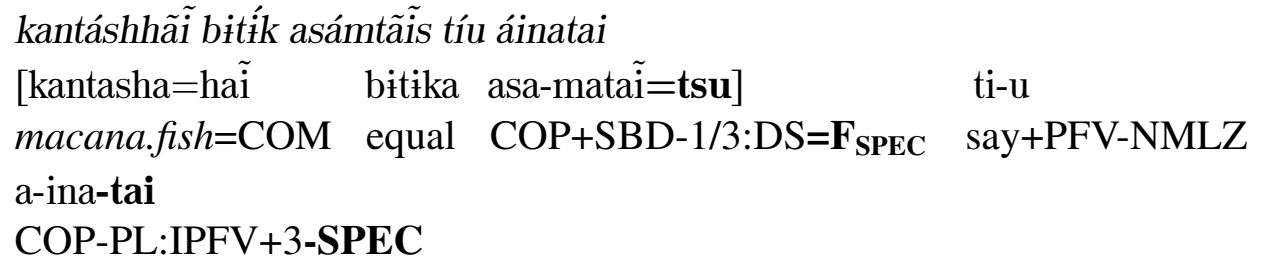

'they say that [because] (probably) it's the same as a macana fish'

The focus feature $=t s u$ falls on the subordinate clause, marking it as the focus of speculation. Interpreting focus on the level of the subordinate clause generates a variable that must be filled by an antecedent which is a set of alternative reasons for why they say that, that has the form of a set of propositions $\{p \mid p \in T\}$. The antecedent must include the proposition it's the same as a macana fish and at least one other reason for the saying event. If focus interpretation of (23) is to be successful (i.e. if the utterance of (23) is to be felicitous), the speaker must have in her head such a set of alternative reasons that can both fill for the extra-linguistic argument $C$ of the speculative operator and serve as the antecedent to the focus-generated variable. ${ }^{10}$

6. Speculating. I have presented the speculative modality as an atomic function over a proposition, involving the speaker and his epistemic alternatives to the proposition. The question remains as to whether this meaning is at-issue or not, and, if not, then what kind of not-at-issue meaning it patterns as. A semantic categorization of the Aguaruna speculative modality (in the manner of Faller's (2014) analysis of the Cuzco Quechua reportative or Murray's (2016) analysis of Cheyenne evidentials) requires the empirical examination of its behavior in a variety of conversational contexts. Given the lack of such data, my brief discussion of these questions will only be speculative in nature.

The speculative mood can be regarded as at-issue meaning in case it "entails a partial or complete answer to QUD [question under discussion]" (Faller 2014). If it does, then it can also be "the target of direct disagreements". We ask whether the Aguaruna equivalent of B or of B' would a direct negation of (2), rendered in English as she probably saw.

(24) A: She probably saw.

B: No, she didn't see.

$\mathrm{B}^{\prime}$ : No, you know for sure that she saw.

\footnotetext{
${ }^{10}$ If we were to interpret focus on the level of the matrix clause, $C$ would be constrained to the set of propositions of the form $\{$ they say that because $p \mid p \in T\}$, containing also the unfocused value of (23).
} 
If only B (in Aguaruna) is a felicitous response to A, we will know that the speculative mood is not at-issue, but only its prejacent proposition. Overall's translations of speculative modality overwhelmingly employ the sentential adverbs probably and perhaps, suggesting that the contribution is not-at-issue; yet example (5) uses modal might I might cut wood, which can be shown to affect the truth conditions of its prejacent proposition and hence carry at-issue meaning (cf. Von Fintel \& Gillies 2007). English response B' is certainly not a felicitous disagreement to A (it would only be felicitous to the complex sentence I'm not sure that she saw). The employment of probably and perhaps in English argues in favor of analyzing the contribution of the speculative modality as also not-at-issue.

If we succeed to establish the not-at-issue status of the speculative clause, it would still remain to determine (in the manner of Faller 2014) whether this not-at-issue meaning is a presupposition, a conventional implicature or illocutionary modifier. Such a classification would require additional data from Aguaruna and is beyond the scope of this discussion. However, given Faller's extensive argument against a conventional implicature analysis of reportatives, a conventional implicature analysis of the speculative clause is ill-fated. In such a view the speculative clause would be a tuple that independently proffers both the unmodalized prejacent proposition together and the not-at-issue speculative meaning: ${ }^{11}$

$$
<p, \operatorname{Speculate}(p)>
$$

The independent status of the prejacent proposition $p$ in the speculative clause would then imply $p$ 's ability to enter the conversational common ground (CG) of the interlocutors (Stalnaker 2002). This property is doubtful, given the speaker's lowered degree of commitment to the truth of the proposition when uttering the speculative clause. It is questionable whether uttering (5) I might cut wood will add the unmodalized proposition I will cut wood to the set of commonly-accepted propositions. Faller highlights Potts's (2007) hesitation about the "twodimensional" meaning interpretation of evidentials: "it is generally hard to determine whether a sentence containing a hedging evidential counts as an assertion of its core propositional content".

A further diagnostic for the precise not-at-issue status of the speculative mood involves examining its embedding behavior. Many such tests are precluded for the simple reason Aguaruna subordinate clauses may only contain non-finite verbs, which are "incompatible with mood/modality marking" (Overall 2018:436) and hence speculative marking. The non-finiteness of subordinate clauses makes it clear that the -tai cannot embed under verbs of saying or attitude, where the speculator becomes the matrix clause subject rather than the speaker; nor can it embed inside an interrogative clause since this would violate the mutual-exclusivity criterion of clause typing (Sadock \& Zwicky 1985). If grammatical speculation were somehow possible inside questions, we would have to ask whether it participates in the interrogative flip (Speas \& Tenny 2003), anchoring the speculation in some way to the addressee of the question.

Since speculation is indicated in the outermost modality slot G, it is also unlikely that it can embed under verbal negation, expressed grammatically in slot $\mathrm{F}$ of a finite verb. This at least seems to be the case with the declarative modality, which scopes over the negated proposition:

\footnotetext{
${ }^{11}$ For simplicity I omit the set of alternatives $C$ from the speculative function in (25), assuming it to be implicit in the speaker's information state.
} 
atsa iki kanas'hai

atsa iki kana-tsu-ha-i

no not.yet sleep+IPV-NEG-1SG-DECL

'no, I'm not sleeping yet'

(Overall 2018:409)

The form -tsu of the negative suffix here is (strikingly) identical to the speculative focus enclitic $=t s u$ (but Overall gives no indication that they are related).

I have presented these compressed and by no means complete diagnostics as a call for future fieldwork on the speculative clause, necessary to more accurately integrate it into the typology of evidentiality systems. I anticipate surveying this typology in search of evidentials that interact with focus as naturally as does the Aguaruna speculative modality, and seeing what further connections between the two phenomena we might draw from such findings.

7. Conclusion. The speculative clause stands out among the Aguaruna clause types in its compact focus paradigm, while the alternative-presupposing nature of speculation lends itself particularly well to interpretation within the alternative semantics framework. Both the speculative-internal focus and the not-at-issue meaning contributed by the speculative clause find parallels cross-linguistically, as is evident from the immediate applicability of Rooth's focus interpretation theory to =tsu and $-t s a$, and the comparisons that have yet to be made between the patterning of other evidentials, such as the Cuzco Quechua reportative evidential, and the Aguaruna speculative modality. Looking deeper within, and further beyond, Aguaruna, we can glean a better typology of the mechanism of focus and its deliberate role in systems of evidentiality.

\section{References}

Faller, Martina. 2014. Reportativity, (not-)at-issueness, and assertion. Berkeley Linguistics Society (BLS) 40. 62-84. https://doi.org/10.3765/bls.v40i0.3133.

Murray, Sarah E. 2016. Evidentiality and illocutionary mood in Cheyenne. International Journal of American Linguistics 82(4). 487-517. https://doi.org/10.1086/688604.

Overall, Simon E. 2018. A grammar of Aguaruna (Iiniá Chicham) (Mouton Grammar Library). Berlin: De Gruyter.

Partee, Barbara. 1991. Topic, focus and quantification. Semantics and Linguistic Theory (SALT) 1. 159-188. https://doi.org/10.3765/salt.v1i0.2918.

Potts, Christopher. 2007. The expressive dimension. Theoretical linguistics 33(2). 165-198. https://doi.org/10.1515/TL.2007.011.

Roberts, Craige. 2012. Information structure: Towards an integrated formal theory of pragmatics. Semantics and Pragmatics 5. 6:1-69. https://doi.org/10.3765/sp.5.6.

Rooth, Mats. 1992. A theory of focus interpretation. Natural Language Semantics 1(1). 75-116. https://doi.org/10.1007/BF02342617.

Rooth, Mats. 2016. Alternative semantics. In Caroline Féry \& Shinichiro Ishihara (eds.), The Oxford handbook of information structure. 19-40. Oxford: Oxford University Press.

Sadock, Jerrold M \& Arnold M Zwicky. 1985. Speech act distinctions in syntax. In Timothy Shopen (ed.), Language typology and syntactic description, Vol. 1. 155-196. Cambridge, UK: Cambridge University Press. 
Speas, Peggy \& Carol Tenny. 2003. Configurational properties of point of view roles. In Anna Maria Di Sciullo (ed.), Asymmetry in grammar, Volume 1: Syntax and semantics. 315-345. Amsterdam: John Benjamins. https://doi.org/10.1075/la.57.15spe.

Spencer, Andrew. 1991. Morphological theory: An introduction to word structure in generative grammar. Hoboken, NJ: Wiley-Blackwell.

Stalnaker, Robert. 2002. Common ground. Linguistics and Philosophy 25(5/6). 701-721. https://doi.org/10.1023/A:1020867916902.

Von Fintel, Kai \& Anthony Gillies. 2007. An opinionated guide to epistemic modality. In Tamar Gendler \& John Hawthorne (eds.), Oxford studies in epistemology, Volume 2. 32-62. Oxford: Oxford University Press. 